\title{
An experimental study on the rate and mechanism of capillary rise in sandstone
}

\author{
Yuya Tsunazawa ${ }^{1 *}$, Tadashi Yokoyama ${ }^{2}$ and Naoki Nishiyama ${ }^{3}$
}

\begin{abstract}
The Lucas-Washburn equation is a fundamental expression used to describe capillary rise in geologic media on the basis of pore radius, liquid viscosity, surface tension, contact angle, and time. It is known that a radius value significantly smaller than the main pore radius must be used in the equation in order for the predictions to fit the experimentally measured values. To evaluate this gap between theoretical predictions and experimental data, we conducted several capillary rise experiments using Berea sandstone. First, to investigate conditions in which pores of any size are available for capillary rise, an experiment was conducted using a dried core. Next, to adjust the size distribution of pore water before the capillary rise, gas pressure was applied to a water-saturated core and water was expelled from pores of $r>10 \mu \mathrm{m}$; then, capillary rise was initiated. Under this condition, capillary rise occurred only in the pores of $r>10 \mu \mathrm{m}$. The same experiment was conducted for $r=3,1$, and $0.36 \mu \mathrm{m}$. When narrower pores were made available for capillary rise, the overall rate of rise decreased and approached the rate observed when the sample was dry initially. This observation suggests that the capillary rise in narrow pores plays a significant role in the overall rate. Based on these results, we propose a conceptual capillary rise model that considers differing radii in branched pores and provide an example of a quantitative description of capillary rise.
\end{abstract}

Keywords: Capillary rise, Capillary pressure, Lucas-Washburn equation, Water expulsion method, Sandstone

\section{Background}

Geologic media commonly have pores of various sizes and shapes. When water comes in contact with a geologic medium, it is drawn into the pores by capillary force. At equilibrium, the height of capillary rise in a vertical pipe with a radius of $r$ at $20{ }^{\circ} \mathrm{C}$ is estimated to be $15,1.5$, and $0.15 \mathrm{~m}$ for $r=1,10$, and $100 \mu \mathrm{m}$, respectively. An understanding of the mechanism and rate of capillary rise is important when considering the transport of water in geologic media near the ground surface (i.e., imbibition and drying), associated processes such as rock weathering and soil formation, water availability to plants, and contaminant migration.

Capillary rise is driven by capillary pressure, $\Delta P$ $(\mathrm{Pa})$, and $\Delta P$ is correlated to pore radius $r(\mathrm{~m})$ as follows:

\footnotetext{
* Correspondence: ytsunazawa@eps.s.u-tokyo.ac.jp

${ }^{1}$ Department of Earth and Planetary Science, Graduate School of Science, The University of Tokyo, 7-3-1 Hongo, Bunkyo-ku, Tokyo 113-0033, Japan Full list of author information is available at the end of the article
}

$$
\Delta P=\frac{2 \gamma \cos \theta}{r}
$$

where $\gamma$ is the surface tension of the water-air interface $(\mathrm{N} / \mathrm{m})$ and $\theta$ is the contact angle. This equation shows that capillary pressure increases with decreasing pore radius. The volumetric flow rate $q$ in a pipe $\left(\mathrm{m}^{3} / \mathrm{s}\right)$ is given by the following Hagen-Poiseuille equation:

$$
q=\pi r^{2} v=\frac{\pi r^{4}}{8 \mu} \frac{\Delta P}{l},
$$

where $l(\mathrm{~m})$ is the length of the pipe, $\Delta P$ is the pressure differential between the inlet and outlet of the pipe (Pa), and $\mu$ is the viscosity of water (Pa s). In addition, if capillary rise in a pipe with a tortuosity of $\tau$ (dimensionless) occurs at a rate of $v(\mathrm{~m} / \mathrm{s})$, we have

$$
\frac{d x}{d t}=\frac{v}{\tau},
$$

where $x$ is the height of capillary rise $(\mathrm{m})(\tau x=l)$ and $t$ is the elapsed time after the onset of capillary rise (s). By combining Eqs. 1-3 with $\tau=1$, the Lucas-Washburn $(\mathrm{L}-\mathrm{W})$ equation is obtained: 


$$
x^{2}=\frac{r \gamma \cos \theta}{2 \mu} t .
$$

This is a fundamental equation for understanding capillary rise in pores. However, it has been found that the $x-t$ relationship predicted by the L-W equation with simple assumptions (e.g., a constant, realistic $r$ and a constant $\theta$ ) does not agree well with measured, experimental data (Dullien et al. 1977; Hammecker et al. 1993). Methods to improve the L-W equation involving change in contact angle (Einset 1996; Siebold et al. 2000; Heshmati and Piri 2014), non-uniformity of pore radius (Dullien et al. 1977; Erickson et al. 2002), tortuosity of pores (Benavente et al. 2002; Cai et al. 2014), non-circularity of the cross section of pores (Benavente et al. 2002; Cai et al. 2014), and inertial effect and pore wall roughness especially at the earliest stage of capillary rise (Szekely et al. 1971) have been discussed. A geologic medium usually has a complex pore structure, and any of the variables $\tau, r$, and $\theta$ can change depending on the position in the medium and the elapsed time of capillary rise. Therefore, it is often not easy to determine which factor most affects the overall rate of capillary rise.

For this study, several different experiments were performed using sandstone, each designed to evaluate the effects of pore size on the rate of capillary rise. We compare experimental results with theoretical predictions based on the L-W equation, discuss the mechanism of capillary rise, and propose a conceptual model that can account for the experimental results.

\section{Methods}

\section{Sample description}

Berea sandstone from Ohio, USA, was used in the experiments. The sandstone is composed of $88.9 \%$ quartz, 3.4 \% feldspar, $2.2 \%$ carbonate, $3.9 \%$ clay, $0.5 \%$ evaporite, and $1.1 \%$ other (Zhan et al. 2010). Figure 1 shows a backscattered electron image of the polished surface of a sample. Typical grain sizes were 150$250 \mu \mathrm{m}$. The open-pore porosity of the sample $\left(\phi_{\text {open }}\right)$ was $18.7-21.9 \%$. The value of $\phi_{\text {open }}$ was determined using " $\phi_{\text {open }}=\left(W_{\text {wet,sat }}-W_{\text {dry }}\right) / V^{\prime}$, where $W_{\text {wet,sat }}$ is the water-saturated sample weight, $W_{\text {dry }}$ is the dry sample weight, and $V$ is the sample volume (water density $=0.998 \mathrm{~g} / \mathrm{cm}^{3}$ at $20{ }^{\circ} \mathrm{C}$ ). The pores were saturated with water under a vacuum following the procedure of Yokoyama (2013). The transport-pore porosity $\phi_{\text {tra }}$, calculated by subtracting the fraction of dead-end pores from the fraction of open pores following the method of Yokoyama and Takeuchi (2009), was $17.6 \%$. Figure 2 shows pore size distribution determined by the water expulsion method (Nishiyama et al. 2012) using an initially water-saturated sample of Berea sandstone. The majority of the pores $(76 \%)$ had radii $\geq 10 \mu \mathrm{m}$. The

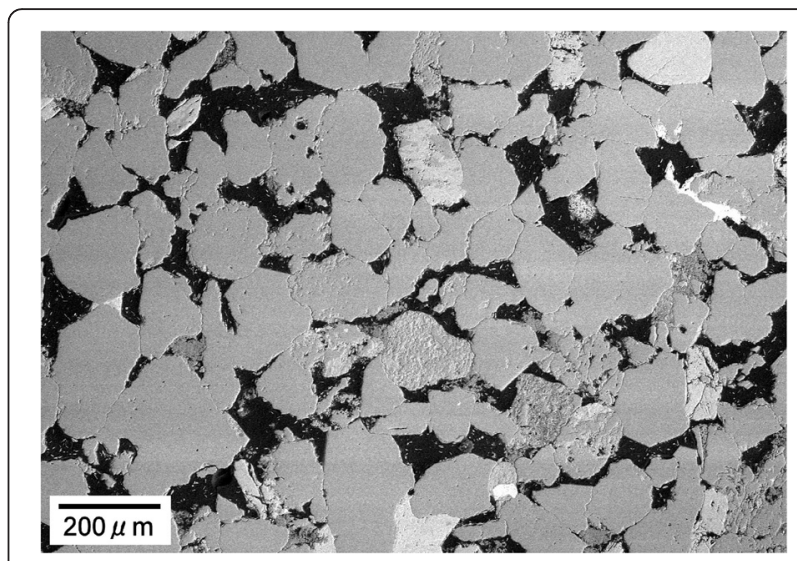

Fig. 1 Backscattered electron image of Berea sandstone. Gray, white, and black correspond to quartz (with minor feldspar and clay), Ca-Mg carbonates, and pores (filled with resin), respectively

fractions of pores with radii of $1-9 \mu \mathrm{m}$ and $<1 \mu \mathrm{m}$ were 22 and $2 \%$, respectively.

In the analysis of capillary rise, we incorporated the effect of pore tortuosity $(\tau)$ into the L-W equation. The value of $\tau$ was determined as follows. First, permeability $(k)$ of the Berea sandstone under saturated conditions was determined by a constant-head permeability test (Yokoyama 2013). The value of $k$ was $2.16 \times 10^{-13} \mathrm{~m}^{2}$ at 20.2-20.6 ${ }^{\circ} \mathrm{C}$, which was determined by Darcy's law, as follows:

$$
\frac{Q}{A}=\frac{k}{\mu} \frac{\Delta P}{L},
$$

where $Q$ is the flow rate $\left(1.13 \times 10^{-8} \mathrm{~m}^{3} / \mathrm{s}\right), A$ is the cross-sectional area of the rock $\left(5.15 \times 10^{-4} \mathrm{~m}^{2}\right), \Delta P$ is the differential pressure of water $\left(1.16 \times 10^{4} \mathrm{~Pa}\right), L$ is the

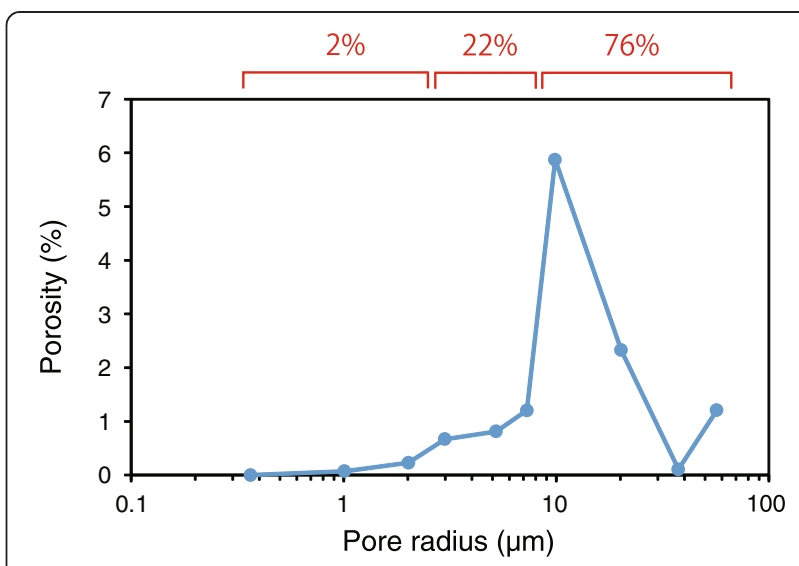

Fig. 2 Pore size distribution of sandstone measured by the water expulsion method. The percentages and ranges at the top of the graph show the volumetric proportion of pores for each pore radius range 
thickness of the rock $\left(1.14 \times 10^{-2} \mathrm{~m}\right)$, and $\mu=1.002 \times$ $10^{-3} \mathrm{~Pa}$.s. For the case of a circular tube of radius $r$, permeability $k$ and pore radii $(r)$ can be correlated by the following Kozeny-Carman relation (Carman 1956; Paterson 1983; Walsh and Brace 1984):

$$
k=\frac{\phi_{\operatorname{tra}} r^{2}}{8 \tau^{2}} .
$$

By inserting measured values of $k, \phi_{\text {tra }}$, and $r\left(1 \times 10^{-5} \mathrm{~m}\right.$ from Fig. 2) into Eq. 6, $\tau$ was calculated to be 3.19 .

\section{Experiment 1: measurement of capillary rise using a dried core}

Figure 3a shows a photograph of the first experiment, which investigated capillary rise using a dried rock core. The rock core was $3.44 \mathrm{~cm}$ in diameter, $15.2 \mathrm{~cm}$ high, and $298.0 \mathrm{~g}$ in dry mass. At the onset, the bottom of the core was dipped in pure water (milliQ) to a depth of approximately $3 \mathrm{~mm}$. The wet and dry portions were visually distinct, and the variation of the height of the wet front over time was monitored. The temperature and relative humidity were $19.4-20.3{ }^{\circ} \mathrm{C}$ and $40.6-47.3 \%$, respectively, measured every $10 \mathrm{~min}$ for the duration of the experiment.

\section{Experiment 2: measurement of capillary rise after} controlling for the size distribution of pore water In experiment 1 , water could infiltrate pores of any size because the sample was initially dry. Also of interest is the rate of capillary rise when pores smaller than a given radius are filled with water before the onset of capillary rise. To achieve this condition, we applied the following water expulsion method. First, the lateral side of a rock core sample $(2.46 \mathrm{~cm}$ in diameter and $4.94 \mathrm{~cm}$ high) was sealed with resin (Technovit, 4004; Fig. 3b), and the sample's pores were filled with water. The sample was installed on an apparatus for water expulsion (Fig. 4a), and gas pressure was applied to the bottom of the sample. When the difference in gas pressure between the top and bottom of the sample ( $\left.\Delta P_{\text {gas }}\right)$ overcomes the capillary pressure in a pore, water in the pore is expelled to the top of the sample. This occurs when the following condition is satisfied:

$$
r>\frac{2 \gamma \cos \theta}{\Delta P_{\text {gas }}}
$$

where $r$ is the radius of pore from which water is expelled (Yokoyama and Takeuchi 2009; Nishiyama et al. 2012; Nishiyama and Yokoyama 2014). Equation 7 shows that the minimum radius of empty pores after water expulsion decreases as $\Delta P_{\text {gas }}$ increases (Fig. 4b). Expelled water was wiped away with tissue, and pores larger than a given radius emptied. After this water expulsion treatment, the sample was weighed, and the capillary rise experiment was initiated (Fig. 3b). The water expulsion treatment was conducted for four pore radii using the same sample: the values of $\Delta P_{\text {gas }}$ applied were 146,485 , 1441 , and $4000 \mathrm{hPa}$, corresponding to radii of 10, 3, 1, and $0.36 \mu \mathrm{m}$, respectively. For comparison, the capillary rise experiment was also carried out with the fully dried sample. In experiment 2, the position of the wet front could not be seen because the sample was sealed with resin. Therefore, the sample was removed from the apparatus intermittently and weighed to determine the amount of water absorbed. The temperature and relative humidity were $17.6-22.0{ }^{\circ} \mathrm{C}$ and $33.1-44.2 \%$,

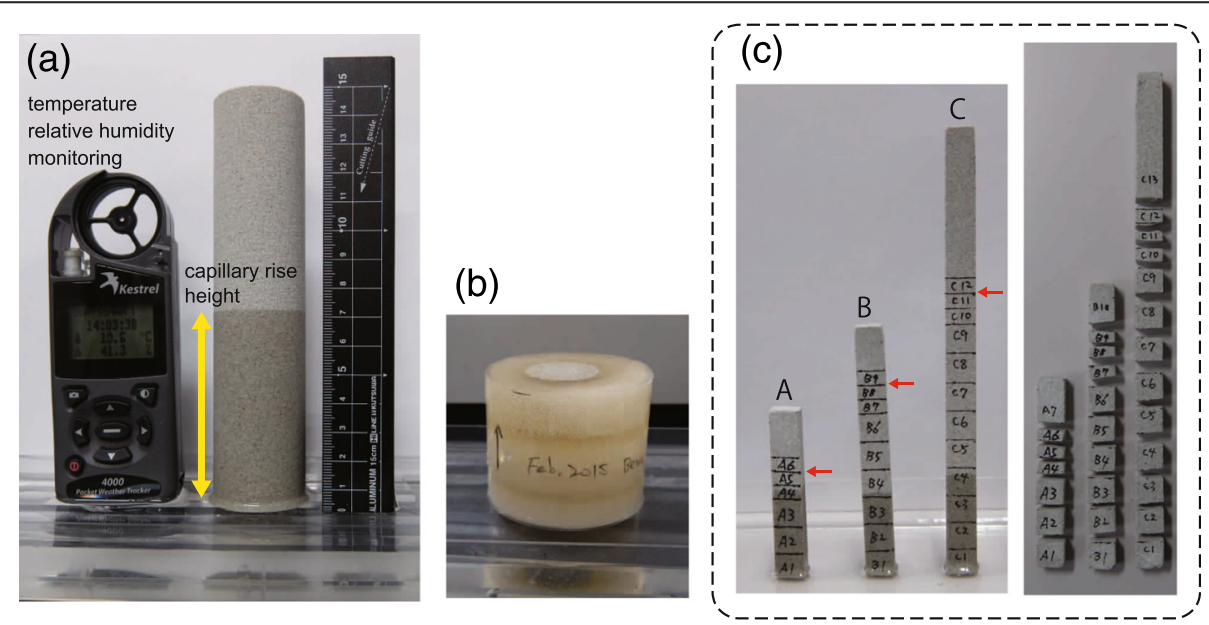

Fig. 3 Photographs of the three types of capillary rise experiments. a Experiment using a dried core without a lateral seal. b Experiment using a core with a lateral seal. Capillary rise was initiated after water in pores with a radius $>10,>3,>1$, or $>0.36 \mu \mathrm{m}$ was expelled. c Experiment for evaluating the height profile of water saturation. Left: during capillary rise; right: after samples are cut 

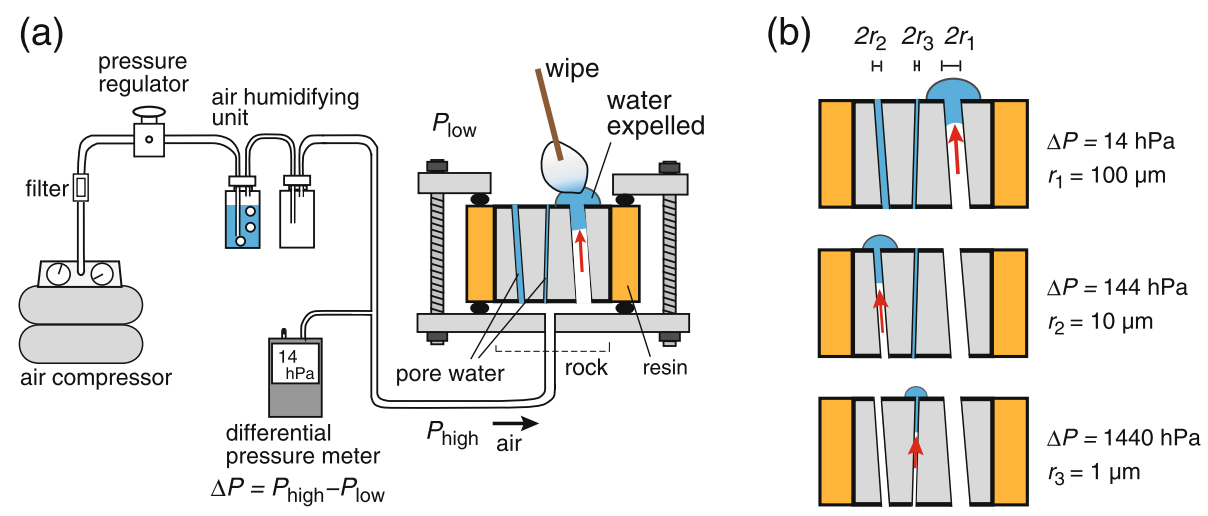

Fig. 4 Schematic illustration of the water expulsion method. a Experimental apparatus. b Diagram illustrating the process of water expulsion through increasing the differential pressure applied to the sample

respectively (humidity was not measured during the experiments for $r=1$ and $3 \mu \mathrm{m}$ ).

\section{Experiment 3: measurement of the height profile of water saturation}

This experiment aimed to evaluate how the height profile of water saturation $(S)$ in the sample changes as capillary rise proceeds. First, stick-shaped samples (A, B, and $\mathrm{C}$ ) approximately $1.0 \mathrm{~cm}$ wide, $0.7 \mathrm{~cm}$ thick, and 6$15 \mathrm{~cm}$ high were cut from Berea sandstone. The bottom of each sample was dipped in pure water to a depth of approximately $3 \mathrm{~mm}$ to initiate capillary rise (Fig. 3c, left). After time had passed such that the height of the wet front rose to $3.7 \mathrm{~cm}$ (sample A), $6.7 \mathrm{~cm}$ (sample B), and $9.7 \mathrm{~cm}$ (sample C), the samples were cut into 7-16 pieces (Fig. 3c, right) using a circular saw (HOZAN K210) without adding water, and each piece was weighed. Then, the pieces were dried, weighed again, and $S$ was determined by

$$
S=\left(W_{\text {wet }, S}-W_{\text {dry }}\right) / \phi_{\text {open }} V,
$$

where $W_{\text {wet }, S}$ is the sample weight at $S$ (water density= $0.998 \mathrm{~g} / \mathrm{cm}^{3}$ ). Samples were cut in intervals of approximately $5 \mathrm{~mm}$ for portions near the wet front and $1 \mathrm{~cm}$ for portions distal to the wet front, except for the dry portion, which was left intact. Times required for the completion of sample cutting ranged from approximately $1 \mathrm{~min}$ (sample A) to approximately $2.7 \mathrm{~min}$ (sample C). To minimize migration of water during cutting, the portions near the wet front were cut first. The temperature and relative humidity during the experiment were $19.3-19.6{ }^{\circ} \mathrm{C}$ and $38.6-40.1 \%$, respectively.

\section{Results and discussion}

\section{Height profile of water saturation}

Figure 5 shows height profiles of $S$ during the capillary rise experiments. Measurements of $S$ at various heights in samples $\mathrm{A}, \mathrm{B}$, and $\mathrm{C}$ are plotted to show vertical trends in capillary rise; arrows show the position of the visible wet front in each sample, i.e., 3.7, 6.7, and $9.7 \mathrm{~cm}$, respectively. From these results, it is observed that $S$ was relatively constant at $0.52 \pm 0.05$ from the bottom of the sample to approximately $70 \%$ of the height of wet front at each stage, above which $S$ decreased rapidly upward toward the wet front. The value of $S$ decreased almost to zero just above the wet front, which indicates that the difference in capillary rise height between the interior and exterior of the samples was small.

\section{Time variation in capillary rise height in initially dry sandstone}

The results of the capillary rise experiment conducted using the dried core are shown in Fig. 6a. The rise of the

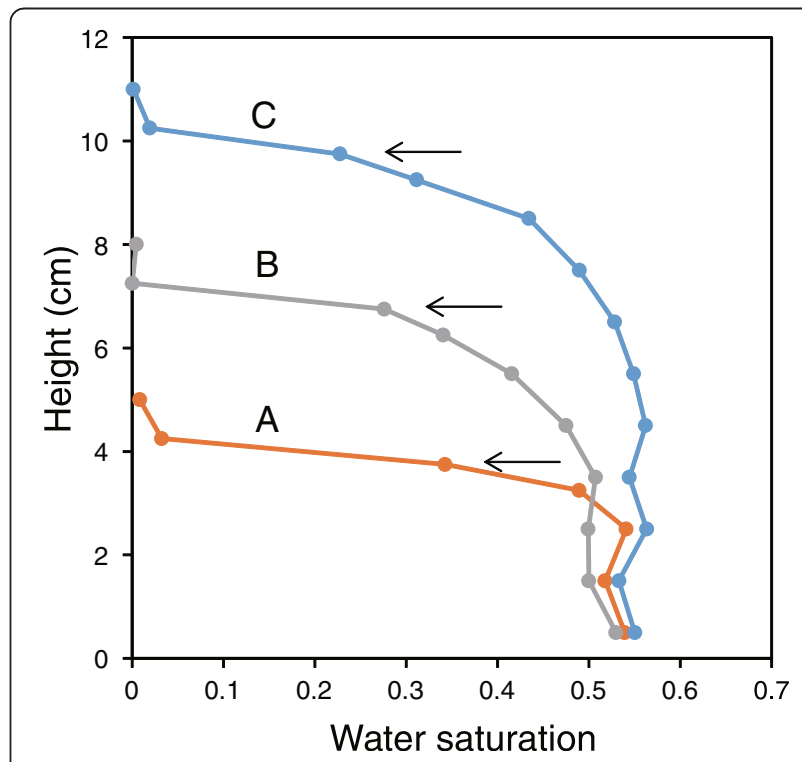

Fig. 5 Time variation in the height profile of water saturation in experiment 3. Arrows show the positions of the wet front in each sample 

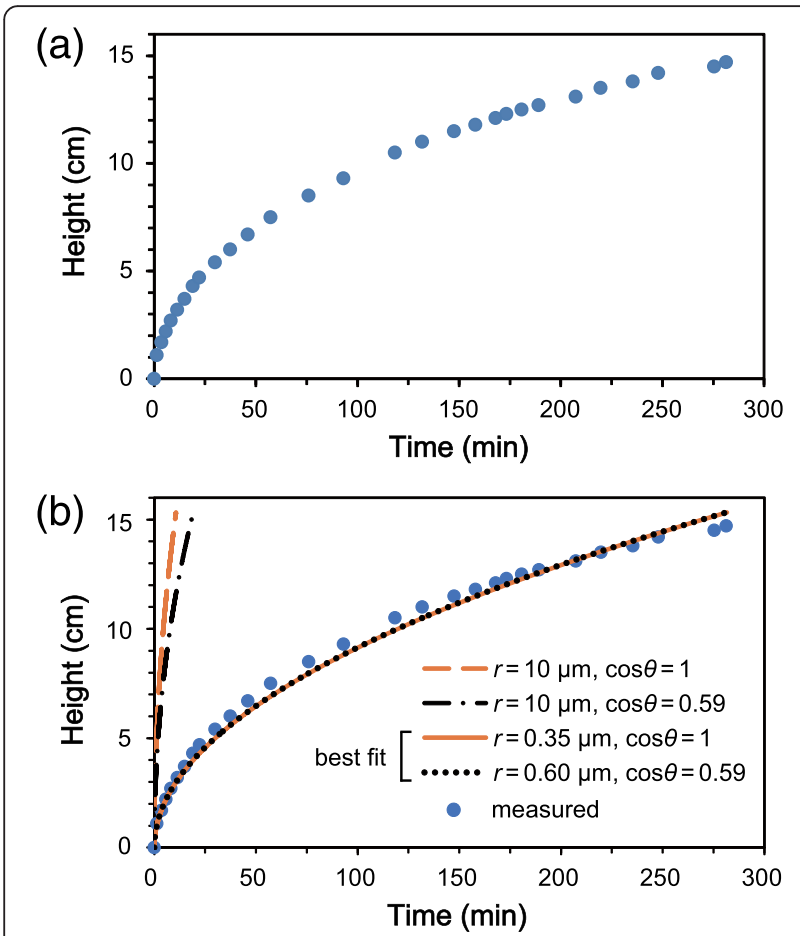

Fig. 6 Measured and calculated values of capillary rise over time. Examples of capillary rise curves calculated using the L-W equation under the conditions of $r=10 \mu \mathrm{m}$ and $\cos \theta=1$ or 0.59 and best fit curves following the L-W equation at $\cos \theta=1$ or 0.59

wet front was rapid at the start of the experiment and gradually slowed over time. As observed in the case of the stick-shaped samples, the difference in capillary rise height between the interior and exterior of the core was small, which was confirmed by observing how the wetting at the top of the core spread at the completion of the capillary rise. The measured capillary rise height can be compared with values calculated using the L-W equation (Eq. 4). The L-W equation is often used in a way that neglects the effects of gravity on the water and the tortuosity of pores, but we considered these factors. Because capillary rise is driven by capillary pressure from which the effect of gravity is subtracted, we have

$$
\Delta P=\frac{2 \gamma \cos \theta}{r}-x \rho g
$$

where $\rho$ is the density of water at $20{ }^{\circ} \mathrm{C}\left(998 \mathrm{~kg} / \mathrm{m}^{3}\right)$ and $g$ is gravitational acceleration $\left(9.80 \mathrm{~m}^{2} / \mathrm{s}\right)$. By inserting Eq. 9 into Eq. 2, the flow rate $q$ becomes

$$
q=\frac{\pi r^{4}}{8 \mu \tau l}\left(\frac{2 \gamma \cos \theta}{r}-x \rho g\right) \text {. }
$$

Thus, $\Delta P$ and $q$ decrease with increasing $x$ and eventually become zero at the equilibrium height. The analytical solution of Eq. 10 with $q=\tau \pi r^{2}(\mathrm{~d} x / \mathrm{d} t)$ is computed as follows:

$$
t=-\frac{8 \mu \tau^{2}}{r^{2} \rho g} x-\frac{16 \gamma \mu \tau^{2} \cos \theta}{r^{3} \rho^{2} g^{2}} \log \left(1-\frac{r \rho g}{2 \gamma \cos \theta} x\right) .
$$

The solution is equal to those of Hamraoui and Nylander (2002) and Fries and Dreyer (2008) if $\tau=1$. The most dominant pore radius in the rock sample is approximately $10 \mu \mathrm{m}$ (Fig. 2); therefore, we initially assume $r=10 \mu \mathrm{m}$. As for $\theta$, the assumption of $\cos \theta=1$ $\left(\theta=0^{\circ}\right)$ has been used previously to analyze capillary rise in sandstone (Dullien et al. 1977; Hammecker and Jeannette 1994) and granitic rocks (Mosquera et al. 2000). In addition, Heshmati and Piri (2014) reported that if capillary numbers $(\mu \nu / \gamma)$ are $<\sim 0.001, \theta$ becomes $\sim 10^{\circ}(\cos \theta=0.98)$ for the case of capillary rise in a glass tube. The capillary number of our sample was calculated to be $<0.001$ for $x>1 \mathrm{~mm}$ based on the measured value of $v$. The assumption of $\cos \theta=1$, therefore, seems to be reasonable. However, the contact angle of quartz, the predominant mineral in Berea sandstone, has been reported to range between $0^{\circ}$ and $54^{\circ}$ (Jaňczuk et al. 1986). Therefore, we also considered the case of $\cos \theta=0.59\left(\theta=54^{\circ}\right)$ as an extreme case. Figure $6 \mathrm{~b}$ shows the variation of water height with time, calculated by Eq. 11 with $\cos \theta=1$ and 0.59 $\left(\gamma=0.0727 \mathrm{~N} / \mathrm{m}\right.$ at $\left.20{ }^{\circ} \mathrm{C}\right)$ and plotted with the measured data. Calculated water heights were significantly higher than the measured values, both in the case of $\cos \theta=1$ and 0.59 .

Table 1 shows the combinations of $r$ and $\cos \theta$ with the measured and calculated values that match best, and the results of $\cos \theta=1 \quad(r=0.35 \mu \mathrm{m})$ and $\cos \theta=0.59$ $(r=0.60 \mu \mathrm{m})$ are shown in Fig. 6b. A higher $\cos \theta$ is associated with a smaller $r$. Even considering wide variation of the contact angle, the calculated values of $r=0.35$ and $0.60 \mu \mathrm{m}$ are significantly smaller than the main pore radii of the rock, which is consistent with the findings of Dullien et al. (1977). This result suggests that the overall rate of capillary rise is related to some process occurring in narrow pores.

\section{Capillary rise after controlling for the size distribution of pore water}

Figure $7 \mathrm{a}-\mathrm{e}$ shows the variation of sample weight over time (dry weight + initial water + newly absorbed water) during the capillary rise experiments beginning after the

Table 1 Pore radius and $\cos \theta\left(\theta=0^{\circ}, 24^{\circ}, 40^{\circ}, 54^{\circ}\right)$ values at which the measured and calculated values match best

\begin{tabular}{lllll}
\hline $\cos \theta$ & 1 & 0.91 & 0.77 & 0.59 \\
$r(\mu \mathrm{m})$ & 0.35 & 0.39 & 0.46 & 0.60 \\
\hline
\end{tabular}



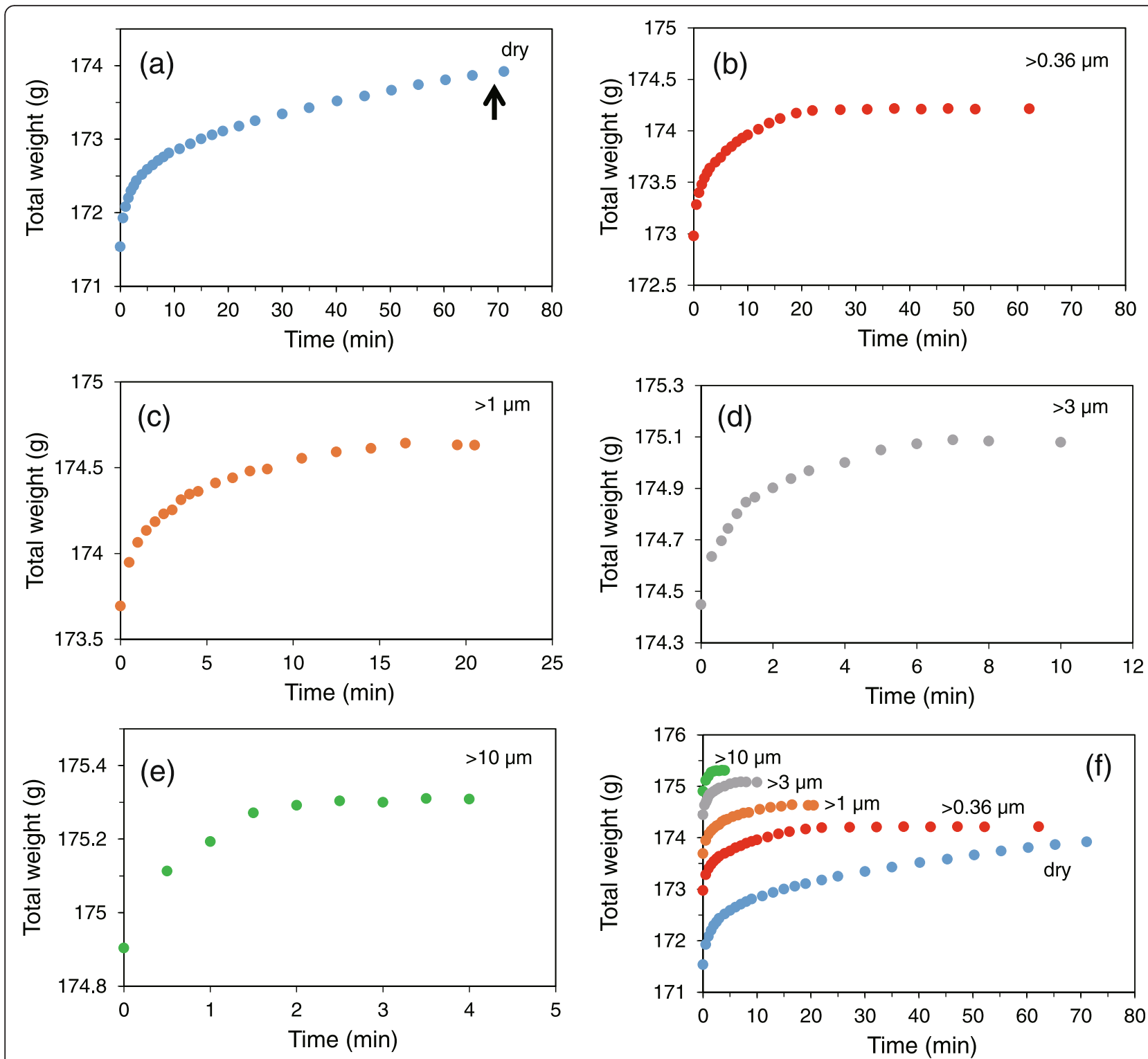

Fig. 7 Sample weight over time during capillary rise after the water expulsion method. The arrow in a indicates the time at which wetting was observed at the top of the core. The experiment was started with a dry sample (a) or a sample in which the water in pores with a radius $>0.36$, $>1,>3$, or $>10 \mu \mathrm{m}$ was expelled (b-e, respectively). The results are summarized in $\mathbf{f}$

water expulsion treatments, and Fig. $7 f$ summarizes these data. As described above, water infiltrates the "empty pores" formed by water expulsion. The position of the wet front cannot be seen in the initially wet samples used for these experiments (Fig. 7b-e), but for the experiment initiated with a fully dried sample (Fig. 7a), the time at which the wet front reached the top of the sample could be visually confirmed $(70 \mathrm{~min}$, arrow in Fig. 7a). The weight was still increasing after $70 \mathrm{~min}$ in the trial, as depicted in Fig. 7a, indicating that water absorption was continuing. Conversely, for the case in which pores $<0.36 \mu \mathrm{m}$ were initially filled with water (Fig. 7b), the weight did not increase after approximately
20 min. Based on the results reported in Fig. 7a, the height of capillary rise in the experiment represented by Fig. 7b likely reached the top of the sample before a stable weight was attained. Therefore, capillary rise after expelling water in pores $>0.36 \mu \mathrm{m}$ occurred much faster than under dry conditions. Likewise, as the size of empty pores increased (Fig. 7c-e), the rate of capillary rise increased, as demonstrated in Fig. $7 f$.

\section{A conceptual model for capillary rise}

Dullien et al. (1977) and Einset (1996) have proposed that non-uniformity of pore radius in a single pore (see Fig. 8a for an example) is a major reason for slower than 


\section{(a) Capillary rise started in an initially dry sample}

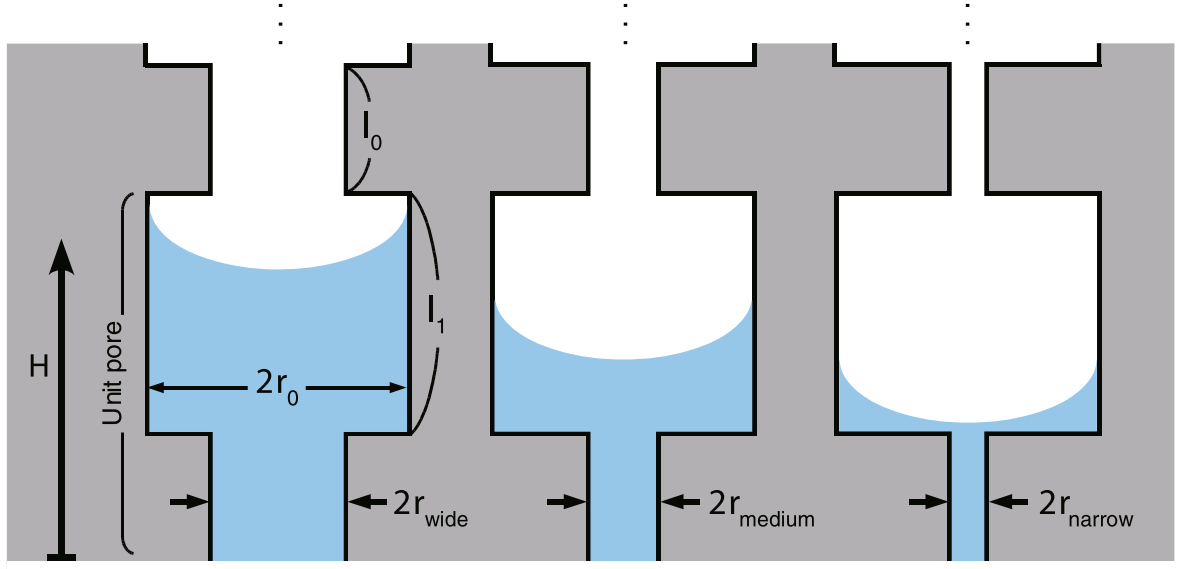

(b) Capillary rise started after expulsion of water in large pore

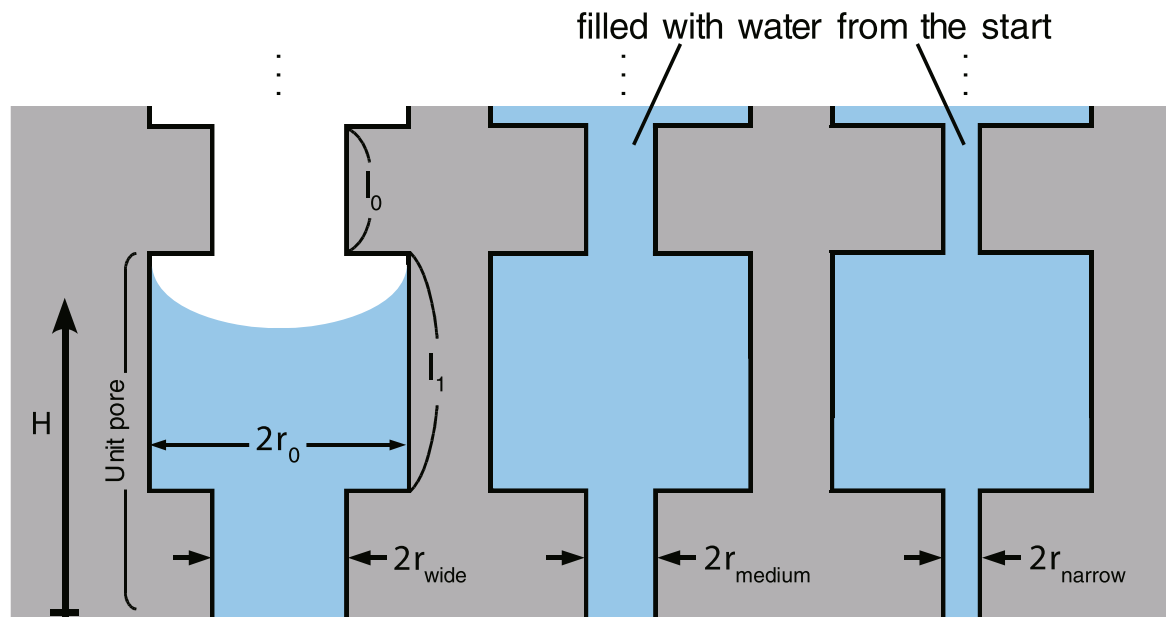

Fig. 8 Effect of non-uniformity of the pore radius, as predicted by Dullien (1977)'s model. No difference of capillary rise height $H$ is predicted whether the experiment was started with a dry sample (a) or a sample that has undergone water expulsion treatment (b)

predicted capillary rise when using the L-W equation with the dominant pore size of a sample. When a pore consists of a narrow part followed by a wider part, the driving force of water at the wide part is relatively weak because of low capillary pressure, while flow resistance in the narrow part is high. Consequently, the rate of capillary rise in such a non-uniform pore is slower than that in a consistently narrow pore. If the porosity of a rock is formed by repeated "unit pores" such as the pores illustrated in Fig. 8a, the effective pore radius $\left(r_{\text {eff }}\right)$ for capillary rise in the rock is given by

$$
r_{\text {eff }}=\left(\sum_{k} l_{k}\right)^{2}\left[\sum_{k} l_{k} \sum_{j}\left(\frac{l_{j}}{2 r_{j}}\right)\left(\frac{r_{k}}{r_{j}}\right)^{3}\right]^{-1},
$$

where $r$ and $l$ are the radius and the length of a component of the unit pore, respectively (Dullien et al. 1977).
The summations represent overall components of the unit pore. In Eq. 12, the factor of $1 / 3$ originally included by Dullien et al. (1977) is excluded because the factor corresponds to the effect of tortuosity, which is already taken into account in this study (Eq. 4 or Eq. 11). If $r_{\text {wide }}=10 \mu \mathrm{m}, r_{0}=30 \mu \mathrm{m}$, and $l_{0}=l_{1}=$ $200 \mu \mathrm{m}$ are assumed on the basis of grain size (Fig. 1) and pore size distribution (Fig. 2), $r_{\text {eff }}$ is calculated to be $1.4 \mu \mathrm{m}$, which means that the rate of capillary rise in the rock is equivalent to that in a pore with a $1.4 \mu \mathrm{m}$ radius, even though the pore radii of the rock are 10 and $30 \mu \mathrm{m}$. Therefore, this effect may partially explain the slow capillary rise indicated by our results. However, this effect is unlikely to be the sole factor; according to Dullien's model (Dullien et al. 1977), the height of capillary rise is predicted to be similar between experiments started with dry samples and with samples 


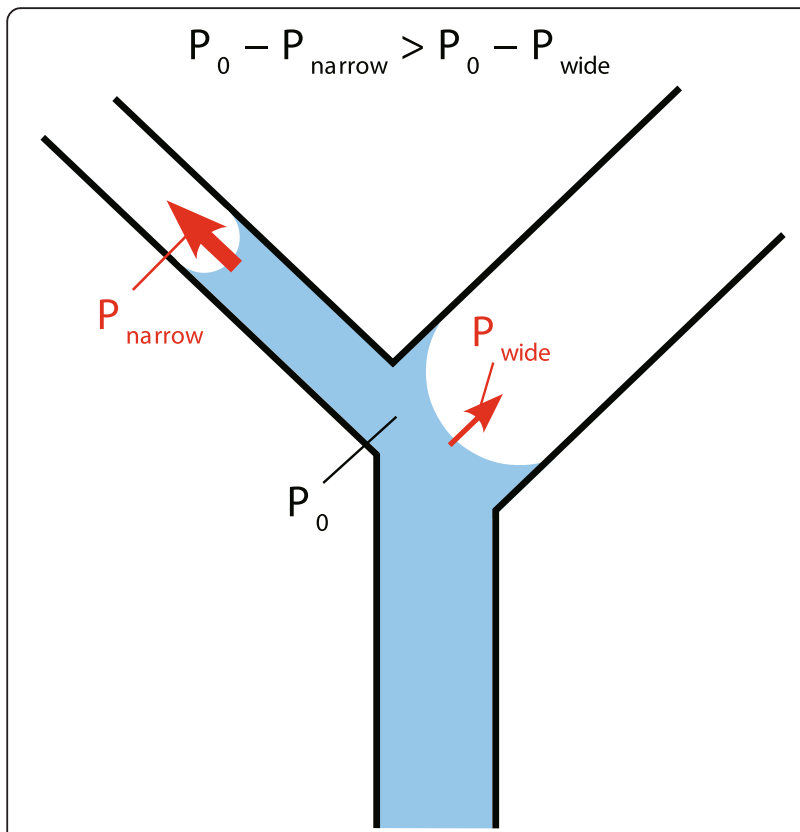

Fig. 9 Capillary rise in Y-shaped piping with different radii, as proposed by Mehrabian et al. (2011) and Sadjadi et al. (2015). Because capillary pressure in narrower pores is greater than that in wider pores, water advances first into narrower pores subjected to water expulsion treatment prior to the experiment, as shown in Fig. 8a, b. This prediction is inconsistent with our results (Fig. 7f).

A theoretical calculation of capillary rise in Y-shaped piping with different pipe radii (Mehrabian et al. 2011) indicates that water selectively advances in the narrower pipe because the capillary pressure in the narrower pipe is greater than that in the wider pipe (Fig. 9). Sadjadi et al. (2015) also reported a similar phenomenon based on theoretical calculations and experimental observations of capillary rise in a simple Y-shaped junction. We extend these concepts to rocks with complex pore structure and propose a conceptual model that accounts for the effect of branched pores with different pore radii (Fig. 10a). When capillary rise occurs in dry conditions (Fig. 10a), water advances through a narrower pore (Fig. 10b), while capillary rise in an adjacent wider pore almost stops near the junction (light backward movement of water front in a wider pore toward the junction may even occur). When water in the narrow pore rises to a certain height ( $l_{\text {resume }}$ in Fig. 10b), the pressure drop in the narrow pore overcomes the difference in capillary pressure between the narrow and wide pores, and water begins to advance up the wide pore. By extending the model presented by Sadjadi et al. (2015), $l_{\text {resume }}$ can be calculated by

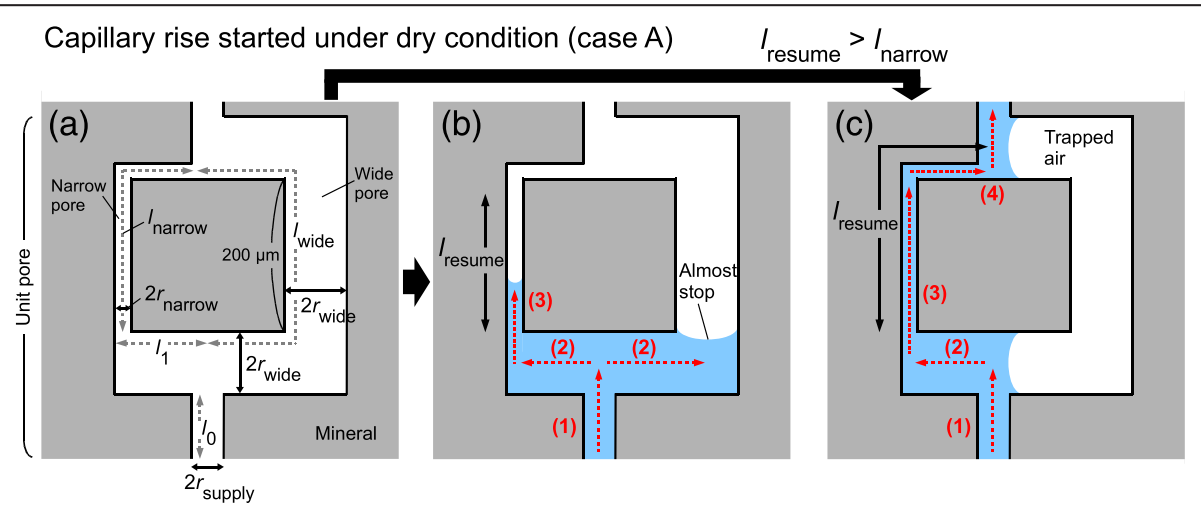

Capillary rise started after water expulsion (case B)
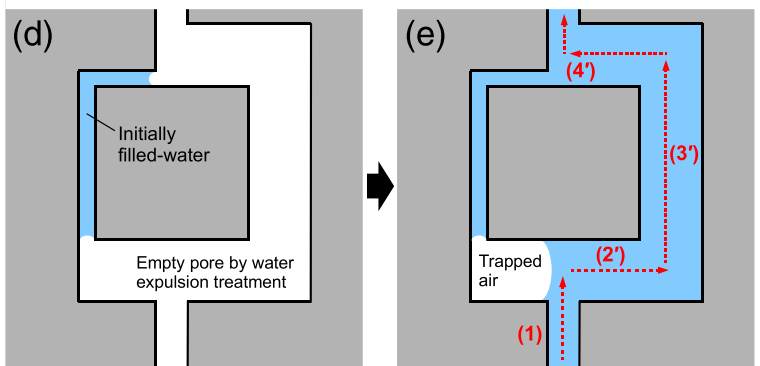

(f)

\begin{tabular}{|c|c|c|c|}
\hline $\begin{array}{c}r_{\text {supply }} \\
(\mu \mathrm{m})\end{array}$ & $\begin{array}{l}r_{\text {wide }} \\
(\mu \mathrm{m})\end{array}$ & $\begin{array}{c}r_{\text {narrow }} \\
(\mu \mathrm{m})\end{array}$ & \\
\hline 10 & 20 & 4 & \\
\hline $\begin{array}{c}I_{0} \\
(\mu \mathrm{m})\end{array}$ & $\begin{array}{l}I_{\text {wide }} \\
(\mu \mathrm{m})\end{array}$ & $\begin{array}{c}I_{1} \\
(\mu \mathrm{m})\end{array}$ & $\begin{array}{c}I_{\text {narrow }} \\
(\mu \mathrm{m})\end{array}$ \\
\hline 200 & 400 & 100 & 300 \\
\hline
\end{tabular}

Fig. 10 Conceptual models of capillary rise in rock pores with a branched structure. a-c Capillary rise in dried rock. d, e Capillary rise after emptying wider pores by water expulsion. $\mathbf{f}$ Values of the radii and lengths of each pore used to calculate $r_{\text {eff }}$ for the sample. These values were chosen based on the grain size and pore size distributions of the sample 


$$
l_{\text {resume }}=l_{\text {supply }}\left(\frac{r_{\text {narrow }}}{r_{\text {supply }}}\right)^{4}\left(\frac{r_{\text {wide }}}{r_{\text {narrow }}}-1\right)-l_{1}\left(\frac{r_{\text {narrow }}}{r_{\text {wide }}}\right)^{4} \text {, }
$$

where $l_{\text {supply }}$ is the distance from the bottom of the rock to the junction. Definitions of the other variables are given in Fig. 10a. In the case that $l_{\text {resume }}>l_{\text {narrow }}$ (Fig. 10c), water in the narrow pore arrives at the next junction faster than the water in the wide pore (path 4 in Fig. 10c) and is likely to trap air in the wide pore. Therefore, the wide pore cannot be used as a path for capillary rise, and, consequently, capillary rise through the narrow pore occurs slowly (path 1-4 in Fig. 10c). If the parameters listed in Fig. 10f are used as an example, and the rock porosity is assumed to be formed by repeated unit pores as in Fig. 10a, then $l_{\text {resume }}$ exceeds $300 \mu \mathrm{m}\left(l_{\text {narrow }}\right)$ when the height of capillary rise $\left(l_{\text {supply }}\right)$ is above $6 \mathrm{~mm}$. Therefore, paths $1-4$ in Fig. 10c are the possible paths of capillary rise under dry conditions, and the corresponding $r_{\text {eff }}$ is determined to be $0.30 \mu \mathrm{m}$. When capillary rise occurs after the water expulsion treatment (Fig. 10d), water can enter the pore on the right (path 2' in Fig. 10e), whereas water probably cannot enter the pore on the left because one end of the pore is blocked by the water filling the narrow pore, which traps air beneath it. Therefore, capillary rise here is expected to progress along the wide pore (paths 1-4' in Fig. 10e). In this case, $r_{\text {eff }}$ is $4.7 \mu \mathrm{m}$, which is larger (i.e., higher capillary rise) than the $r_{\text {eff }}$ determined under dry conditions $(0.30 \mu \mathrm{m})$. As the radius of water-filled pores increases, the rate of capillary rise is expected to increase because the overall path of capillary rise widens, as seen in the comparison of Fig. 11a, b. The result illustrated in Fig. $7 \mathrm{f}$ supports the validity of this model.

Inertia has also been considered to explain deviations between the measured rate of capillary rise and predictions made using the L-W equation (e.g., Bosanquet 1923; Quéré 1997). Theoretical studies and experiments conducted using a capillary pipe demonstrated that the height of capillary rise dominated by inertial force is proportional to time (Quéré 1997; Siebold et al. 2000), whereas the L-W equation shows that the height of capillary rise governed by viscous force is proportional to the square root of time. Because the height of capillary rise in our sample did not increase linearly with time (Fig. 6), the effect of inertia is likely to be negligible, at least for the time span considered in this study. (a)

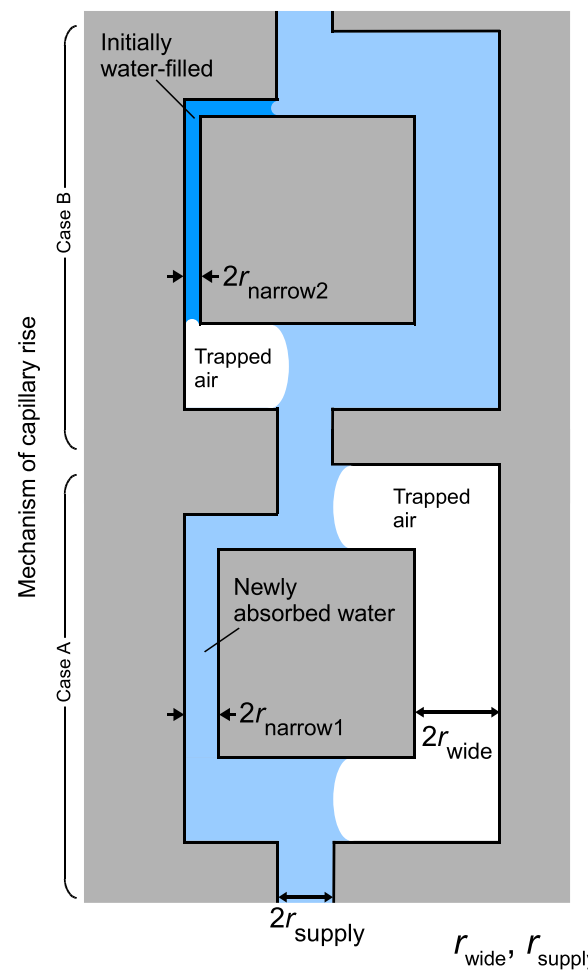

(b)

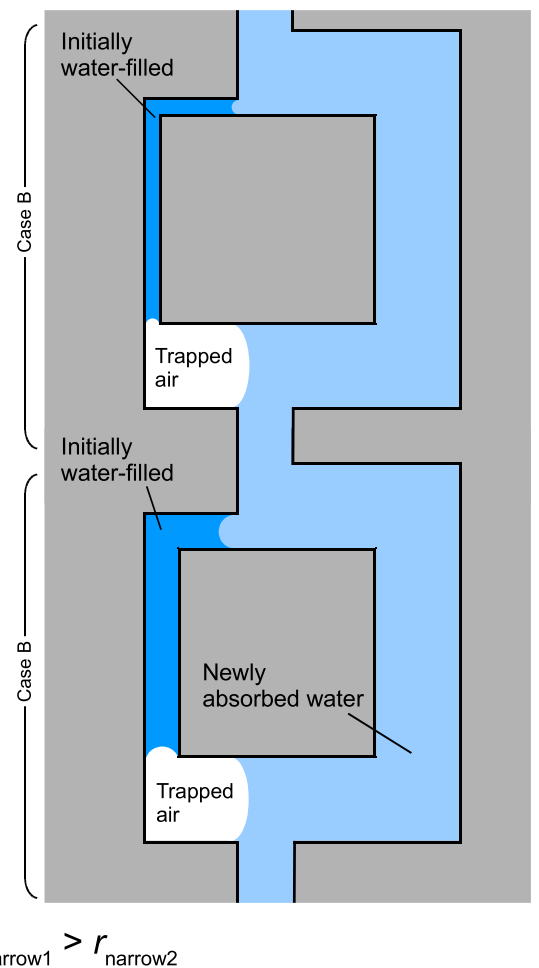

Fig. 11 Conceptual models of capillary rise after the water expulsion treatment with different $\Delta P$ in Eq. 7. a Only the pores with a radius of $r_{\text {narrow2 }}$ are initially water-filled. (b) The pores with radii of $r_{\text {narrow1 }}$ and $r_{\text {narrow2 }}$ become water-filled. Water advances depending on whether the narrower pore is filled with water (case a or b in Fig. 10) 


\section{Conclusions}

To evaluate the relationship between the rate of capillary rise and pore size, capillary rise experiments using Berea sandstone were conducted using controlled size distribution of pore water, and the results were analyzed using the L-W equation. The key results and interpretations are as follows:

(1) A pore radius value significantly smaller than dominant pore radius of the rock had to be used to reproduce the experimental results using the L-W equation, assuming $\cos \theta=1$ and a uniform pore radius.

(2) In the experiment that was initiated with a dry sample, water saturation in the sample was relatively constant below approximately $70 \%$ of the height of the wet front and decreased rapidly with increasing height toward the wet front.

(3) As the radius of the pores available for capillary rise decreased, the rate of capillary rise decreased and approached that of the initially dry sample.

(4) The effect of the nonuniformity of pore radii in a single flow path can explain the result of (1) at least partly but is unlikely to account for the result of (3). These results can be better explained by considering the capillary rise in branched pores with different pore radii.

\section{Abbreviations}

L-W: Lucas-Washburn.

\section{Competing interests}

The authors declare that they have no competing interests.

\section{Authors' contributions}

YT conducted the experimental study and analyzed the data. TY proposed the topic and designed the study. NN helped interpret the experimental results. All authors collaborated to write the manuscript and approved the final manuscript.

\section{Acknowledgements}

We thank two anonymous reviewers for their helpful comments.

\section{Author details}

'Department of Earth and Planetary Science, Graduate School of Science, The University of Tokyo, 7-3-1 Hongo, Bunkyo-ku, Tokyo 113-0033, Japan. ${ }^{2}$ Graduate School of Integrated Arts and Sciences, Hiroshima University, 1-7-1 Kagamiyama, Higashi-Hiroshima, Hiroshima 739-8521, Japan. ${ }^{3}$ Research Center for Functional Materials, National Institute for Materials Science, 1-1 Namiki, Tsukuba, Ibaraki 305-0044, Japan.

Received: 31 October 2015 Accepted: 12 April 2016 Published online: 28 April 2016

\section{References}

Benavente D, Lock P, García Del Cura MÁ, Ordóñez S (2002) Predicting the capillary imbibition of porous rocks from microstructure. Transport Porous Med 49:59-76

Bosanquet H (1923) On the flow of liquids into capillary tubes. Philos Mag Ser 6: 525-531

Cai J, Perfect E, Cheng C-L, Hu X (2014) Generalized modeling of spontaneous imbibition based on Hagen-Poiseuille flow in tortuous capillaries with variably shaped apertures. Langmuir 30:5142-5151
Carman PC (1956) Flow of gases through porous media. Elsevier, New York Dullien FAL, El-Sayed MS, Batra VK (1977) Rate of capillary rise in porous media with nonuniform pores. J Colloid Interface Sci 60:497-506

Erickson D, Li D, Park CB (2002) Numerical simulations of capillary-driven flows in nonuniform cross-sectional capillaries. J Colloid Interface Sci 250:422-430

Einset EO (1996) Capillary infiltration rates into porous media with applications to silcomp processing. J Am Ceram Soc 79:333-338

Fries N, Dreyer M (2008) The transition from inertial to viscous flow in capillary rise. J Colloid Interface Sci 327:125-128

Hammecker C, Mertz JD, Fischer C, Jeannette D (1993) A geometrical model for numerical simulation of capillary imbibition in sedimentary rocks. Transport Porous Med 12:125-141

Hammecker C, Jeannette D (1994) Modelling the capillary imbibition kinetics in sedimentary rocks: role of petrographical features. Transport Porous Med 17:285-303

Hamraoui A, Nylander T (2002) Analytical approach for the Lucas-Washburn equation. J Colloid Interface Sci 250:415-421

Heshmati M, Piri M (2014) Experimental investigation of dynamic contact angle capillary rise in tubes with circular and noncircular cross sections. Langmuir 30:14151-14162

Jaňczuk B, Chibowski E, Białopiotrowicz T (1986) Time dependence wettability of quartz with water. Chem Papers 40:349-356

Mehrabian H, Gao P, Feng JJ (2011) Wicking flow through microchannels. Phys Fluids 23:122108

Mosquera MJ, Rivas T, Prieto B, Silva B (2000) Capillary rise in granitic rocks: interpretation of kinetics on the basis of pore structure. J Colloid Interface Sci 222:41-45

Nishiyama N, Yokoyama T, Takeuchi S (2012) Size distributions of pore water and entrapped air during drying-infiltration processes of sandstone characterized by water-expulsion porosimetry. Water Resour Res 48, W09556

Nishiyama N, Yokoyama T (2014) Estimation of permeability of sedimentary rocks by applying water-expulsion porosimetry to Katz and Thompson model. Eng Geol 177:75-82

Paterson MS (1983) The equivalent channel model for permeability and resistivity in fluid-saturated rock - a re-appraisal. Mech Mater 2:345-352

Quéré D (1997) Inertial capillary. Europhys Lett 39:533-538

Sadjadi Z, Jung M, Seemann R, Rieger H (2015) Meniscus arrest during capillary rise in asymmetric microfluidic pore junctions. Langmuir 31:2600-2608

Siebold A, Nardin M, Schultz J, Walliser A, Oppliger M (2000) Effect of dynamic contact angle on capillary rise phenomena. Colloid Surface A 161:81-87

Szekely J, Neumann AW, Chuang YK (1971) The rate of capillary penetration and the applicability of the Washburn equation. J Colloid Interface Sci 35:273-278

Walsh JB, Brace WF (1984) The effect of pressure on porosity and the transport properties of rock. J Geophys Res 89:9425-9431

Yokoyama T, Takeuchi S (2009) Porosimetry of vesicular volcanic products by a water-expulsion method and the relationship of pore characteristics to permeability. J Geophys Res 114, B02201

Yokoyama T (2013) Characterization of the reaction and transport properties of porous rhyolite and its application to the quantitative understanding of the chemical weathering rate. Geochim Cosmochim Acta 118:295-311

Zhan X, Schwartz LM, Toksoz MN, Smith WC, Morgan FD (2010) Pore-scale modeling of electrical and fluid transport in Berea sandstone. Geophysics 75:135-142

\section{Submit your manuscript to a SpringerOpen ${ }^{\circ}$ journal and benefit from:}

- Convenient online submission

- Rigorous peer review

- Immediate publication on acceptance

- Open access: articles freely available online

- High visibility within the field

- Retaining the copyright to your article

Submit your next manuscript at $>$ springeropen.com 